\title{
KLIPPEL-FEIL SYNDROME: A CASE REPORT AND REVIEW OF LITERATURE
}

\author{
Mohammad $\mathrm{H}^{1^{*}}$, Annongu IT ${ }^{1}$, Mue $\mathrm{DD}^{2}$, Chia $\mathrm{DM}^{1}$, Abah $\mathrm{RO}^{3}$, Magaji $^{4} .^{4}$ \\ Department of Radiology ${ }^{1}$, Department of surgery ${ }^{2}$ and Department of Paediatrics ${ }^{3}$, Benue State University Teaching Hospital, \\ Makurdi. \\ Department of Radiology Dalhatu Araf Specialist Hospital, Lafia. ${ }^{4}$
}

"Corresponding Author: Mohammad H, Department of Radiology, Benue State University Teaching Hospital, Makurdi, Nigeria, E-mail: $\underline{\text { drhameed2001@yahoo.com }}$

Received date: March, $05^{\text {th }}, 2018$, Accepted date: March $26^{\text {th }}, 2018$. Published date: April $20^{\text {th }}, 2018$

Abstract
Though Klippel-Feil syndrome is a rare congenital anomaly and the clinical presentations are varied, a
complete history, physical and radiological examinations may reveal the diagnosis.

Keywords: Klippel-Feil syndrome, Congenital, radiological findings, management options.

\section{Introduction}

Klippel-Feil syndrome is a congenital fusion of the cervical vertebrae that may involve two segments, a congenital block vertebra, or the entire cervical spine. Congenital cervical fusion is a result of failure of normal segmentation of the cervical somites during the third to eighth week of life. ${ }^{1,2,3,4}$ The skeletal system may not be the only system affected during this time; cardiorespiratory, genitourinary, and auditory systems frequently are involved. In most patients, the exact cause is unknown. One proposed cause is a primary vascular disruption during embryonic development that results in fusion of the cervical vertebrae and other associated anomalies. ${ }^{5}$

Klippel-Feil syndrome is a rare anomaly occurring in 1 of 42,000 births with a female predominance and a mean age at the time of diagnosis being 3years. ${ }^{6,7,8}$ In 1912, Maurice Klippel and Andre Feil independently provided the first descriptions of Klippel-Feil syndrome in patients who manifested the following: Short webbed neck, decreased range of motion (ROM) in the cervical spine and low hairline. Feil subsequently classified the syndrome into the following three types: Type I - Massive fusion of the cervical spine, Type II - Fusion of one or two vertebrae and Type III - Presence of thoracic and lumbar spine anomalies in association with type I or type II Klippel-Feil syndrome. Since the original description, other classification systems have been advocated to describe the anomalies, predict the potential problems, and guide treatment decisions. Samartzis et al suggested their own classification system, which stratified patients as follows: Type I Single-level fusion, Type II -Multiple, noncontiguous fused segments, Type III - Multiple, contiguous fused segments ${ }^{9}$. Gray et al described 462 patients with Klippel-Feil syndrome and found that the level of fusion did not greatly affect the incidence of neurologic symptoms. The most frequent level they identified was a defect of the occiput to $\mathrm{C} 1, \mathrm{C} 2$, and C3. These produced the most symptoms; lesions below C3 and 4 were slightly less likely to cause symptoms. $^{10}$

Current literature suggests that there is paucity of reported cases of this anomaly in our environment. Certain types of Klippel-Feil syndrome may be unrecognized clinically; therefore, the physician is required to maintain a high index of suspicion. Missed diagnosis until adult life may result in bony 
malformation which may entrap and damage the brain and the spinal cord ${ }^{2}$ with consequent morbidity and mortality.

This report is a case of Klippel-Feil anomaly in a one-year-old child.

\section{Case Report}

M. A. is a one-year-old male child who was brought by his parents to the Paediatrics Outpatient Department (POPD) of the University of Maiduguri Teaching Hospital (UMTH), Maiduguri, with complaint of recurrent cough since childhood. There was no history of contact with anybody with chronic cough. There was no history of fever or night sweats. The parents also complained that the child has been unable to walk despite being one year old. The patient is the only child in a monogamous setting. There is no history of congenital anomaly in the families of both parents. The father is a trader, while the mother is a full-time housewife. Pregnancy and delivery were uneventful. There was no history of exposure to irradiation, ingestion of traditional herbal medication or febrile illness during pregnancy. There was also no history of drug ingestion except her routine antenatal drugs consisting of anti malarials and folic acid. Patient was fully immunized for age according to NPI schedule.

Physical examination showed a fully alert boy who was afebrile, acyanosed, anicteric and had no peripheral lymphadenopathy. There was a limitation of flexion and extension of the head in the backward and forward directions. There was also a limitation of movement in the lateral direction. His respiratory rate was 30/min. The chest was deformed (fig. 1 and 2). The air entries on both sides were normal.

The cardiovascular, abdominal, central nervous system and Ear, nose and throat (ENT) examinations were normal. Electrocardiography (ECG), Echocardiography, transfontanelle and abdominal ultrasound examinations were also normal. Plain radiographs, anterior-posterior (AP) and lateral (LAT) views of the cervical spine showed multiple hemivertebrae. There was partial fusion of the spinous processes of $\mathrm{C} 1, \mathrm{C} 2$ and $\mathrm{C} 3$ (fig.3).

Plain chest radiograph, AP view showed multiple deformed ribs. Also, plain radiographs, AP and LAT views of the dorsal-lumbar spine showed scoliosis of the lumbar spine with convexity to the right. Both the thoracic and lumbar regions showed multiple fused hemivertebrae. The interpedicular distances were increased. Magnetic Resonance Imaging (MRI) of the brain was done and it was normal. MRI spine, axial and sagittal sequences of T1-and T2-weighted images of the spine were obtained. The T1-weighted images showed ill definition of the vertebrae. The T2weighted images (fig.4) showed fusion of $\mathrm{C} 1$ with $\mathrm{C} 2$ vertebrae. The mid thoracic vertebrae were fused. Multiple fused lumbar vertebrae were also noted. The spinal canal proximal to this was dilated. There was tethering of the cord at $1^{\text {st }}$ and $2^{\text {nd }}$ sacral vertebrae. Multiple fused spinal processes in the thoracic and lumbar regions were also noted. Based on the clinical and imaging findings, a diagnosis of Klippel-Feil anomaly type 3 was made.

The patient was treated for the cough and was on a follow up at the Pediatrics Out Patient Department. The patient stopped coming after the $3^{\text {rd }}$ visit. 


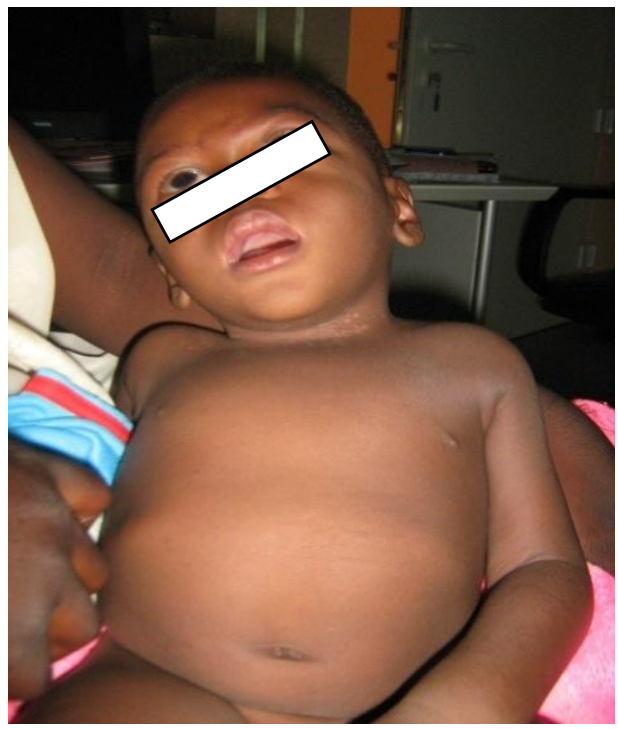

Figure 1 shows the clinical photograph of one-year-old child with Klippel-Feil syndrome. The child has a short neck and deformed chest.

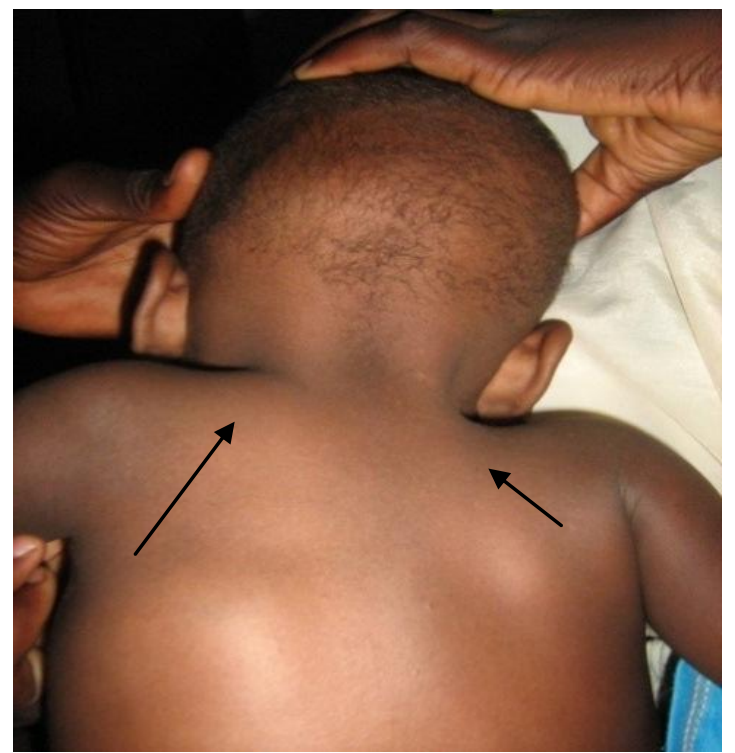

Figure 2: shows the clinical photograph of the same child as above. Note the deformities on upper part of the back (arrows). The hairline appears low. 


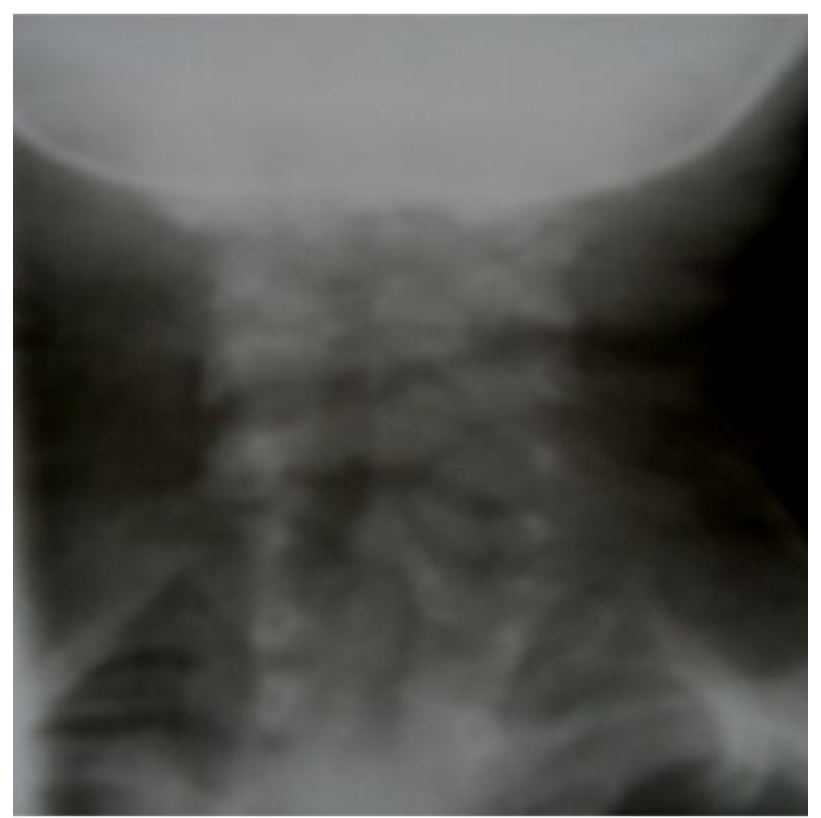

Figure 3: plain Anteroposterior radiograph of the neck of the child showing multiple partially fused hemi-vertebrae.

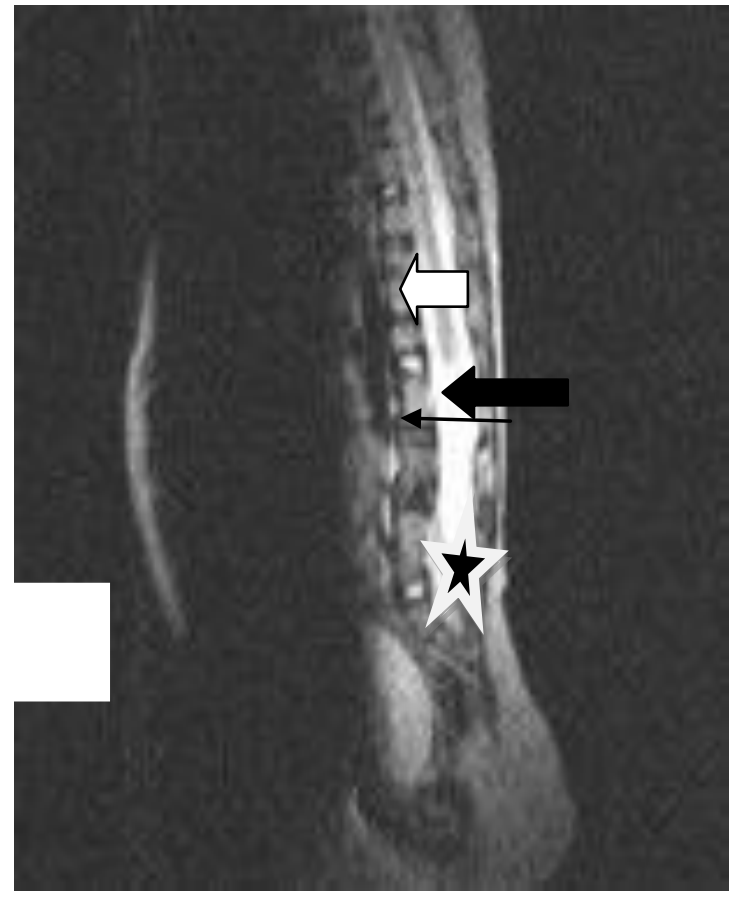

Figure 4: T2- weighted MR image sagittal view of the thoracic and lumbar spines showing multiple fused hemi-vertebrae (arrow head and thin arrow). There is tethering of the spinal cord at the $1^{\text {st }}$ and $2^{\text {nd }}$ sacral piece (star). There is dilatation of the lower theca sac (bold arrow). 


\section{Discussion}

The clinical features of KFS depend largely on the severity of the anomaly, associated congenital deformity and the complications that may arise from these. Most patients present with the classical clinical triad of short neck, limitation of head and neck movements and low posterior hairline. ${ }^{8}$ This index patient presented with all these clinical features.

There is also a common association between KlippelFeil syndrome and Sprengel deformity of the scapular. At least 25 percent of patients with KlippelFeil syndrome have Sprengel deformity, and 40 percent of patients with Sprengel deformity have associated Klippel-Feil syndrome ${ }^{1}$. Sprengel deformity was not seen in this patient. Other associated abnormalities like scoliosis, spina bifida occulta, absence of rib, conductive hearing loss, unilateral renal ectopia with dilated collecting system, microtia, preaxial polydactyly, omovertebral bone, hypoplastic right thumb, choanal atresia, anemia, ventricular septal defect, cleft palate and rib defects have also been reported. ${ }^{5,6}$ Apart from scoliosis and rib defect, none of the above-mentioned anomalies was seen in our patient.

The evaluation of patients with KFS involves the use of plain films, Computed Tomography (CT), Ultrasonography and MRI. ${ }^{11,12}$ Plain radiographs will display only vertebral fusion. Minor vertebral anomalies may be associated with major hind brain anomalies. In such cases magnetic resonance imaging is the ideal modality as it will also show degenerative disc diseases which may complicate the vertebral fusion. ${ }^{12}$ Though CT was not done for the patient due to the fact that at the time of presentation, the machine was not in order, the combination of plain radiographs and MRI were able to demonstrate the lesions.

The management of KFS is largely conservative. According to Samarizis et al. surgery is indicated if myelopathy or radiculopathy does not improve with conservative management. ${ }^{13}$ Indeed, patients with mechanical symptoms caused by degenerative joint disease usually respond to traction, a cervical collar, and analgesics. Neurological symptoms should be evaluated carefully to locate the exact pathological condition; surgical stabilization with or without decompression may be required. Prophylactic fusion of a hypermobile segment is controversial. The risk of neurological compromise must be weighed against the further reduction in neck motion, and this decision must be made for each patient individually. Cosmetic improvement after surgery has been limited, but surgical correction of Sprengel deformity can significantly improve appearance, and occasionally soft-tissue procedures such as Z-plasty and muscle resection improves cosmesis.

Good prognosis is expected in minimally involved patients with Type 1 \& 2 Klippel-Feil syndrome as they lead normal, active lives with no significant restrictions or symptoms. More severely involved patients with Type $3 \& 4$ Klippel-Feil syndrome may have a good prognosis if genitourinary, cardiopulmonary, and auditory problems are treated early.

\section{References}

1. Erin $\mathrm{CP}$, William SP. Klippel-Feil syndrome. In: kirks D (ed). Practical peadiatric imagingdiagnostic radiology of infants and children. $2^{\text {nd }}$ edn. Little, Brown and company. Boston. 1991; 250-251.

2. Patel PR, Lauerman WC. Maurice Klippel. Spine 1995; 20: 2157-2217.

3. Thomsen MN, Schneider U, Weber M. Scoliosis and congenital anomalies associated with KlippelFeil syndrome type I-III. Spine 1997; 22: 396401.

4. Raas-Rothschild A, Goodman RM, Meyer S, Katznelson MB. Klippel-Feil anomaly with sacral agenesis - an additional subtype. Type IV. J Craniofac Genet Dev Biol 1988; 8: 297-301.

5. Greenspan A, Cohen J, Szabo RM. Klippel-Feil syndrome - an unusual association with Sprengel deformity, omovertebral bone, and other skeletal, haematologic and respiratory disorders. A case Report. Bull Hosp Jt Dis Ortho Inst Spring 1991; 51:54-62.

6. Lagravère $\mathrm{MO}$, Barriga $M$, Valdizán $C$, Pardo JF. The Klippel-Feil Syndrome: A Case Report. J Can Dent Assoc 2004; 70: 685-8.

7. Fernandes T, Costa C. Klippel-Feil Syndrome with other associated anomalies in a Portuguese Skeleton. J Anat 2007; 211: 881-885. S

8. Nagib MG, Maxwell RE, Chou SN. Identification and management of high-risk patients with 
Klippel-Feil syndrome. J Neurosurg 1984; 6: $523-$ 553.

9. Samartzis DD, Herman J, Lubicky JP. Classification of congenitally fused cervical patterns in Klippel-Feil patients: epidemiology and role in the development of cervical spinerelated symptoms. Spine. 2006 Oct 1. 31(21):798804.

10. Gray SW, Romaine CB, Skandalakis JE. Congenital fusion of the cervical vertebrae. Surg Gynecol Obstet. 1964: 118:373-85.

11.Ulmer JL, Elster AD. Klippel-Feil syndrome: CT and MR of acquired and congenital abnormalities of cervical spine and cord. J Comput Assist Tomogr 1993; 17 2: 215-239.

12. Guille JT, Miller A, Bowen JR, Frolin E. The natural history of Klippel-Feil syndrome: clinical, roentgenographic, and magnetic resonance imaging findings at adulthood. J Pediat Orthop 1995; 15: 617-26.

13. Samartzis DD, Kalluri P, Herman J, Lubicky JP, Shen FH. 2008 Young Investigator Award: The role of congenitally fused cervical segments upon the space available for the cord and associated symptoms in Klippel-Feil patients. Spine.2008; 33(13):1442-50. [Medline]. 